\title{
Rainfall thresholds and flood warning: an operative case study
}

\author{
V. Montesarchio, F. Lombardo, and F. Napolitano \\ Department of Hydraulics, Highways and Roads, "Sapienza" University of Rome, 00184 Rome, Italy \\ Received: 4 April 2008 - Revised: 8 January 2009 - Accepted: 19 January 2009 - Published: 16 February 2009
}

\begin{abstract}
An operative methodology for rainfall thresholds definition is illustrated, in order to provide at critical river section optimal flood warnings. Threshold overcoming could produce a critical situation in river sites exposed to alluvial risk and trigger the prevention and emergency system alert. The procedure for the definition of critical rainfall threshold values is based both on the quantitative precipitation observed and the hydrological response of the basin. Thresholds values specify the precipitation amount for a given duration that generates a critical discharge in a given cross section and are estimated by hydrological modelling for several scenarios (e.g.: modifying the soil moisture conditions). Some preliminary results, in terms of reliability analysis (presence of false alarms and missed alarms, evaluated using indicators like hit rate and false alarm rate) for the case study of Mignone River are presented.
\end{abstract}

\section{Introduction}

Floods analysis aims to face residual risk, due to failure of technical systems, or due to the rare flood which exceeds the design flood. Forecasting catastrophic events with advance allows civil protection measures to restrain the socioeconomic impact.

Naturally, the flood forecasting methods are different in relation to the basins size and time of concentration (Rosso, 2002). If a $12 \mathrm{~h}$ advance warning is needed, necessarily the forecasting methods are based on different parameters. For large basins $\left(>10000 \mathrm{~km}^{2}\right)$ the concentration time is higher then $10 \mathrm{~h}$ and the flood forecast warning in one section can be made on the basis of the water levels recorded in upstream sections. For intermediate basins $\left(400-10000 \mathrm{~km}^{2}\right)$ the con-

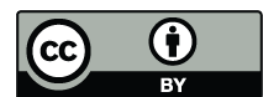

Correspondence to: V. Montesarchio (valeria.montesarchio@uniroma1.it) centration time varies between 3 and $10 \mathrm{~h}$ and the flood forecasting can be made mainly on the basis of precipitation measurements, eventually integrated with forecasted precipitation. For small basins $\left(<400 \mathrm{~km}^{2}\right)$, the concentration time is smaller than $3 \mathrm{~h}$, and the flood forecasting warning can be made only on the basis of precipitation forecasts.

Warning methods work in the precipitation domain and provide rainfall thresholds (in terms of rainfall rate, duration and space extent) for river system critical state. Threshold overcoming could produce a critical situation in river sites exposed to alluvial risk and trigger the prevention and emergency system alert (Georgakakos, 1995).

In this work the critical rainfall thresholds for Mignone River cross section are defined to set a warning for critical flood events. This paper is developed as follows: firstly, an overview of the methodology for rainfall thresholds estimation is given. Secondly, the methodology is applied to the case study of Mignone River. Finally, rainfall thresholds reliability is evaluated and results are discussed.

\section{Flood rainfall thresholds}

Generally, rainfall thresholds identify precipitation critical values, that could be used both in the context of landslides and debris flow hazard forecasting (Neary et al., 1987; Annunziati et al., 1996; Crosta and Frattini, 2000) and in the flood forecasting or warning (Carpenter et al., 1999; Mancini et al., 2002; Georgakakos, 2006; Martina et al., 2006).

In the flood warning context, when critical values are overcame, effects of flooding are expected. Rainfall thresholds specify the precipitation amount for a given duration that generates a critical discharge in a given cross section.

\subsection{Critical cross section identification}

In this study critical cross sections are identified from the available history data and hydraulic geometry. Given the

Published by Copernicus Publications on behalf of the European Geosciences Union. 
hydraulic geometry, critical water stage is known and critical discharge is estimated by the stage-discharge curve (Rosso, 2002).

When the basin is ungauged, neither hydraulic geometry or hydraulic data are known, so is more difficult to establish which is the critical cross section and relative discharge. For choosing the critical cross section, the first element is however the historical one, with information about past floods events. This knowledge allows to identify hydraulic risks areas. If there are no past events recorded, it does not mean that in the future flood events will not occur. It is also possible that in the past flood events occurred, but there is no information available. A way to identify hydraulic risks section is to refer to hydraulic risks planning (i.e. in Italy "Piani di Assetto Idrogeologico" or "Piani Stralcio di Assetto Idrogeologico", in which possible flooding areas are identified), often based on a methodology that allows to identify both critical cross sections and critical discharge (or hydraulic stage), the hydraulic simulation. It requires, however, to know some cross sections of the river, to perform at least one-dimensional flow propagation.

However, in case of no available information, the most critical section could be identified as the outlet of the basin, as all the upstream contributions flow in this section, arriving from the entire drainage area.

Assuming that the critical cross section was identified, the next step is to evaluate the critical discharge. As it has been told, it is more difficult when stream flow data (or stage data and stage-discharge curve) are not available, and the hydraulic modelling is not possible. A feasible solution is to use regional method to evaluate the critical discharge. For example, the flood index method (Dalrymple, 1960) could be used. This method, based on the statistical regionalization, allows to replace the time with the space and to use the set of hydrometric observations of a homogeneous area to fit the lack of discharge data in the critical cross sections.

Given a return period $T$ relative to the critical cross sections, the peak discharge is expressed as the product of two terms: the scale factor of the examined site (the index flood) and the dimensionless growth factor, which has regional validity. Naturally, the index flood of the site and the growth factor of the homogeneous region need to be estimated. In gauged sections it is clearly possible to estimate the index flood directly, by calculating the arithmetic mean of the available observations, in ungauged sections indirect methods have to be used (Brath et al., 2001). Using this approach, the rainfall thresholds is not referred to a critical discharge value, but to different return periods discharge (i.e. 2, 5, 10, $20,50,100$ years).

\subsection{Simulation model}

The methodology is based on the hydrological simulation: the river basin closed at the critical cross section is outlined with a rainfall/runoff model, opportunely calibrated. The in- verse hydrologic problem is iterative solved to identify, for given duration $d$, the cumulative rainfall correspondent to the critical discharge.

When the basin is ungauged, the calibration is more difficult, because of the lack of observed data. The literature however contains numerous studies on the possibly approaches. First of all, it can be used a model including only physically based parameter that can be measured, with no calibration procedures. A second possibility is to extrapolate the parameters of the ungauged sites from those of gauged sites, using regression analysis: in this case could be difficult to relate all model parameters with proper catchment characteristics (Nathan and McMahon, 1990; Servat and Dezetter, 1993; Sefton and Boorman, 1997). Then, there is the possibility of relating the response of the catchment to its morphologic or topologic aspects, using a geomorphologic approach: geomorphologic IUH (GIUH) (Rodriguez-Iturbe and Valdes, 1979) or width function based IUH (WFIUH) (Kirkby, 1976; Mesa and Mifflin, 1986; Naden, 1992). Finally, calibration is possible using synthetic flow duration curves generated for ungauged sites based on regional analysis methods (Yu and Yang, 2000). Thus the methodology could be applied also at ungauged sites, in a more general framework of regional analysis methods, with a grater effort in the model calibration phase, not based on observed data but on opportunely obtained synthetic values. Once the model is calibrated, the inverse hydrologic problem is solved for different return period discharge (cfr. Sect. 2.1).

In this study a semi-distributed rainfall/runoff model is chosen, to consider spatial variability of physical processes. In fact, even if the threshold will be expressed in terms of cumulative precipitation, it seems important to evaluate the variability of response with spatial variability of input, because critical situation could be triggered by local phenomena, and a semi-distributed model allows to highlight these effects.

\subsection{Rainfall thresholds evaluation}

The critical reference discharge could be reached and overcame for different space-time configurations of rain fields. One possible simplified solution is to evaluate globally the cumulative precipitation $(P)$ over the basin, after a time $(d)$ from the beginning of the thunderstorm. Rainfall thresholds are generally function of the critical cross section characteristics, but also of the boundary conditions and the rain event type, especially:

- soil imbibition condition at the beginning of thunderstorm;

- temporal evolution of precipitation.

To evaluate their role, the first parameter was summarised using the AMC (Antecedent Moisture Condition) (SCS, 1971, 1986) index, while the second was simply outlined using four standards hyetotypes (cfr. Sect. 4). 


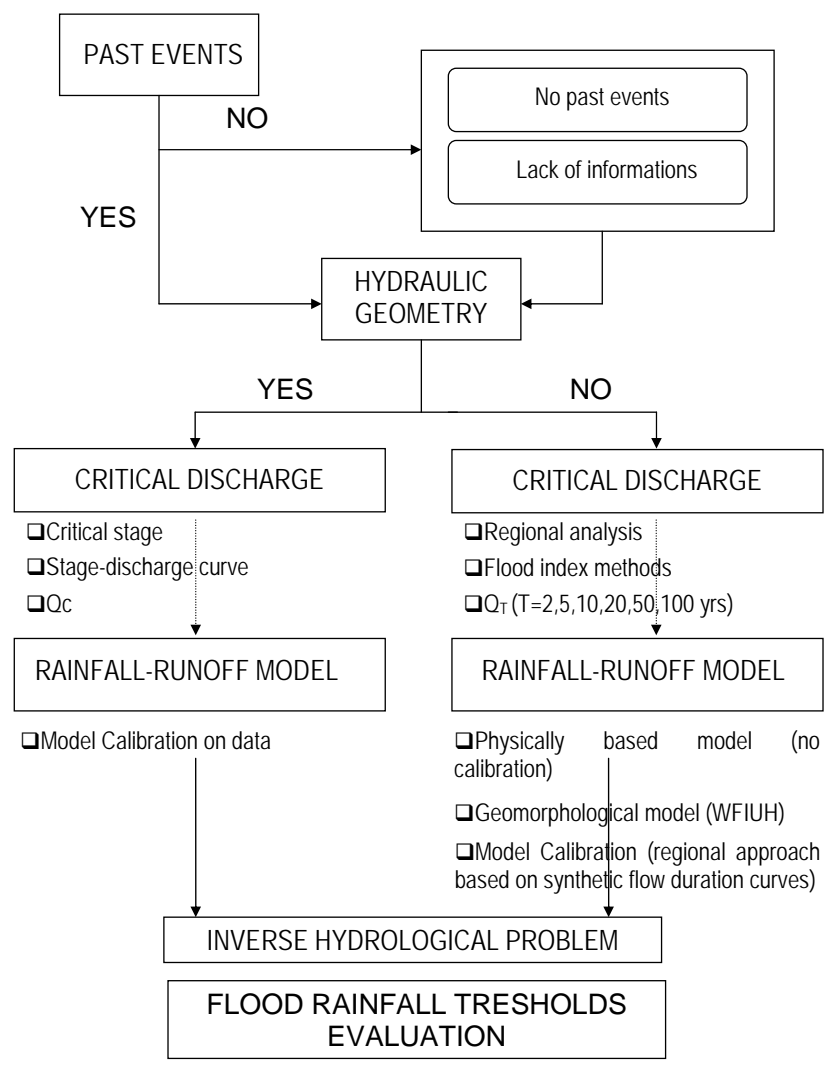

Fig. 1. Flood rainfall thresholds evaluation.

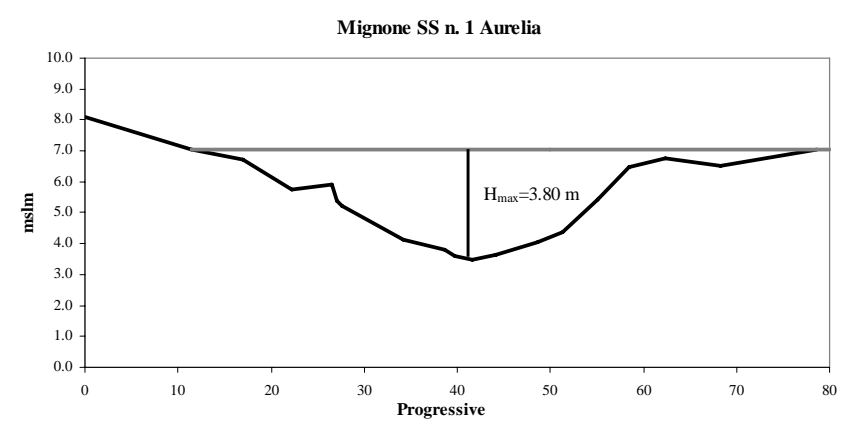

Fig. 2. Critical section hydraulic configuration.

Figure 1 illustrated the steps of rainfall thresholds evaluation procedure.

\section{The case study: Mignone River}

\subsection{Basin characteristics}

The Mignone River begins on the Sabatini Mounts (633 m.s.1. m) and flows into the Tirreno Sea. The river total length is $62 \mathrm{~km}$. The basin surface is about $560 \mathrm{~km}^{2}$, the average elevation is $233 \mathrm{~m}$ a.s.l. The hydraulic behaviour is very variable, typical of a torrential regimen.
Table 1. Initial conditions: API5 (SCS, 1986).

\begin{tabular}{lcc}
\hline AMC Class & \multicolumn{2}{c}{ 5-days antecedent rainfall API5 $(\mathrm{mm})$} \\
\hline & dormant season & growing season \\
I dry & $<12.7$ & $<35.5$ \\
II average & $12.7 \div 28.0$ & $35.5 \div 53.3$ \\
III saturated & $>28.0$ & $>53.3$ \\
\hline
\end{tabular}

Table 2. Rain gauges events AMC (SCS, 1986) classification.

\begin{tabular}{ccc}
\hline AMCI & AMCII & AMCIII \\
\hline 16 & 5 & 7 \\
\hline
\end{tabular}

The soil is constituted by the $25 \%$ of vulcanites, in corrispondence of the reliefs. Coming down towards valley are present sand and conglomerates (14\%), clays (9\%), antropiti (2\%), but above all Flysch (41\%) and alluvial deposits along the river $(9 \%)$.

\subsection{Mignone River: data sets}

\subsubsection{Critical cross section identification}

In this work the critical hydraulic cross section is identified by a preliminary historical-documentary analysis of past flood events.

From the information available on Sistema Informativo Catastrofi Idrogeologiche (SICI) of CNR-GNDCI website it was found that in the last century Mignone River overflowed 3 times (08/11/1934, 27/12/1959, 16/11/1962) in Tarquinia area along the S.S. Aurelia. In first approximation, it has been considered the overflowed fluvial cross sections coinciding with the monitored cross sections "S.S. Aurelia" (drainage area $440 \mathrm{~km}^{2}$ ), therefore identified as critical cross section. Given cross section geometry (Fig. 2) and stagedischarge curve used by authorities, the critical reference discharge, $Q c$ was identified to be equal to $131.0 \mathrm{~m}^{3} / \mathrm{s}$.

\subsubsection{Hydrometric and pluviometric data}

Hydrometric and pluviometric data (from 1999 to 2007) were used both in rainfall/runoff model calibration and validation and in reliability rainfall thresholds evaluation. To take in account soil initial imbibition conditions, given the complex time-space dynamics, a synthetic index, related to antecedent precipitation (Table 1), was chosen. In Table 2 the events are classified in the 3 AMC classes of Soil Conservation Service (USDA, 1971, 1986): type I, dry soil; type II, average conditions and type III saturated soil. In Table 3 are reported date and peak discharge of the floods events interesting the 
Table 3. Flood events in Mignone River Basins.

\begin{tabular}{lr}
\hline date & $Q_{p}\left(\mathrm{~m}^{3} / \mathrm{s}\right)$ \\
\hline $15-20 / 04 / 1999$ & 135.41 \\
$14-17 / 12 / 1999$ & 69.57 \\
$31 / 03-02 / 04 / 2000$ & 103.06 \\
$09-13 / 04 / 2000$ & 422.09 \\
$28 / 01-01 / 02 / 2001$ & 207.36 \\
$11-14 / 12 / 2002$ & 160.33 \\
$05-08 / 01 / 2003$ & 179.38 \\
$26-29 / 11 / 2003$ & 235.17 \\
$04-08 / 05 / 2004$ & 101.04 \\
$04-07 / 12 / 2004$ & 498.03 \\
$25-31 / 12 / 2004$ & 530.89 \\
$18-21 / 01 / 2005$ & 88.24 \\
$02-06 / 03 / 2005$ & 367.75 \\
$08-11 / 09 / 2005$ & 63.96 \\
$05-07 / 11 / 2005$ & 233.21 \\
$25-28 / 11 / 2005$ & 333.66 \\
$02-05 / 12 / 2005$ & 217.43 \\
$05-07 / 12 / 2005$ & 210.72 \\
$08-11 / 12 / 2005$ & 260.18 \\
$01-04 / 01 / 2006$ & 68.18 \\
$19-24 / 02 / 2006$ & 518.54 \\
$05-08 / 03 / 2006$ & 399.52 \\
$15-18 / 03 / 2006$ & 490.69 \\
$16-19 / 09 / 2006$ & 110.81 \\
$20-23 / 10 / 2006$ & 78.55 \\
$08-10 / 12 / 2006$ & 171.69 \\
$08-11 / 02 / 2007$ & 144.98 \\
$24-27 / 03 / 2007$ & 248.63 \\
\hline
\end{tabular}

Mignone River Basin from 1999 to 2007, for which pluviometric data are available.

\subsubsection{Radar data}

The Polar $55 \mathrm{C}$ is located $15 \mathrm{~km}$ south-east of Rome, in the Tor Vergata research area (lat. $41^{\circ} 50^{\prime} 24^{\prime \prime} \mathrm{N}$, lon. $12^{\circ} 38^{\prime} 50^{\prime \prime} \mathrm{E}, 102 \mathrm{~m}$ above sea level). Polar 55C is a Cband $(5.5 \mathrm{GHz}, \lambda=5.4 \mathrm{~cm})$. Doppler weather radar with polarization ability and with a $0.9^{\circ}$ beamwidth. The radar has the capability to transmit and receive horizontally and vertically polarized signals on alternate pulses, allowing not only the measurement of the widely used horizontally reflectivity factor $(Z h)$, but also the differential reflectivity $(Z d r)$ and the differential phase shift ( $\Phi d p)$. Radar measurements are obtained by averaging 64 pulses with a range-bin resolution of $75 \mathrm{~m}$, covering an area with a radius up to $120 \mathrm{~km}$ from the radar site. The temporal resolution is five minutes.

To remove spurious returns from the data, a polarimetrybased ground clutter removal algorithm was applied (Lombardo et al., 2006).

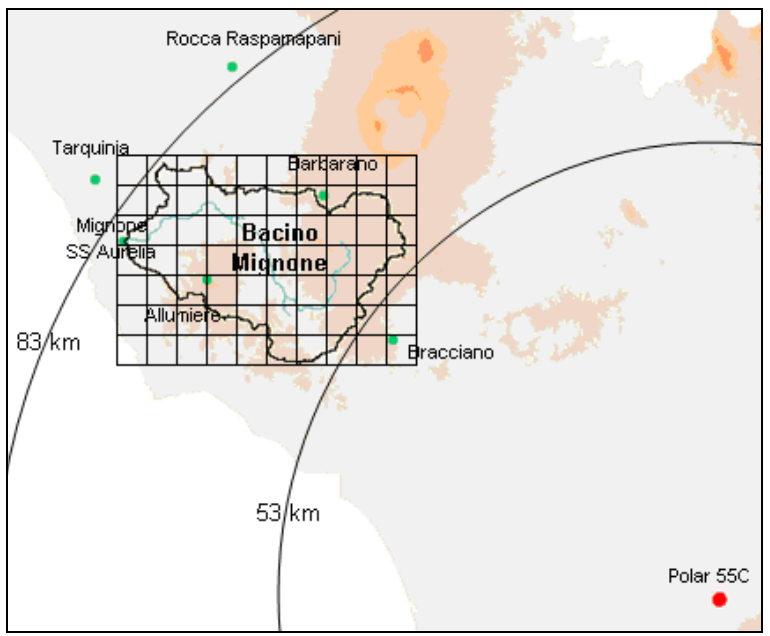

Fig. 3. Study area and radar position.

Table 4. Radar events AMC (SCS, 1986) classification.

\begin{tabular}{ccc}
\hline AMCI & AMCII & AMCIII \\
\hline 6 & 3 & 2
\end{tabular}

In order to convert the radar data into rainfall rates, was used an algorithm based on a $Z-R$ relation. For $C$-band by means of a non-linear regression analysis, the following $Z-R$ relation was obtained (Russo et al., 2005):

$R=7.27 \times 10^{-2} Z_{h}^{0.62}$

where $Z_{h}$ is the reflectivity factor $\left[\mathrm{mm}^{6} \cdot \mathrm{mm}^{-3}\right]$ and $R$ is rainfall intensity $\left[\mathrm{mm} \cdot \mathrm{h}^{-1}\right]$.

After a transformation from Polar to Cartesian coordinates, a regular grid $(2 \mathrm{~km} \times 2 \mathrm{~km})$ over the basin was built (Fig. 3). From each time interval rain intensity values for each pixel were obtained intensity and then total cumulative rainfall Radar rainfall temporal resolution is $30 \mathrm{~min}$.

Radar measurements are classified in AMC classes in Table 4 . It is to be underlined that the radar data not coincide with the floods events summarized in Table 3. In fact, as it is shown in Table 5, only the November 2003 events is covered by both radar and raingauges. Other radar measurements were taken in not flood periods.

\subsection{Simulation model}

A preliminary estimation of main hydrological parameters was derived from the DEM, using the program HECGeoHMS (HEC, 2003a). The obtained values have been used as first attempt values in the calibration of rainfall/runoff models implemented in program HEC-HMS (HEC, 2003b), used in this work for modelling rainfall/runoff transformation. 
Table 5. Radar measurement intervals.

\begin{tabular}{|c|c|c|c|c|}
\hline \multicolumn{4}{|c|}{ Measurement interval } & \multirow{2}{*}{$\begin{array}{r}Q_{p}\left(\mathrm{~m}^{3} / \mathrm{s}\right) \\
0.25\end{array}$} \\
\hline $22 / 10 / 2003$ & 6.25 .34 & $23 / 10 / 2003$ & 7.31 .34 & \\
\hline $26 / 11 / 2003$ & 6.56 .02 & $27 / 11 / 2003$ & 18.46 .46 & 235.17 \\
\hline $26 / 02 / 2004$ & 10.35 .53 & $27 / 02 / 2004$ & 7.00 .53 & 30.01 \\
\hline $01 / 03 / 2004$ & 8.08 .04 & $01 / 03 / 2004$ & 15.20 .53 & 55.43 \\
\hline $11 / 03 / 2004$ & 8.50 .57 & $11 / 03 / 2004$ & 16.40 .54 & 14.73 \\
\hline $24 / 03 / 2004$ & 12.57 .59 & $25 / 03 / 2004$ & 14.30 .34 & 7.16 \\
\hline $07 / 05 / 2004$ & 8.07 .59 & $07 / 05 / 2004$ & 16.36 .34 & 37.69 \\
\hline $12 / 05 / 2004$ & 5.42 .59 & $12 / 05 / 2004$ & 16.41 .35 & 5.71 \\
\hline $14 / 05 / 2004$ & 8.16 .34 & $14 / 05 / 2004$ & 18.16 .35 & 3.28 \\
\hline 05/08/2004 & 8.55 .55 & 05/08/2004 & 17.31.35 & 0.09 \\
\hline
\end{tabular}

The basin area was subdivided in two subbasins (Fig. 4): the first closed to Rota and the second closed to the critical cross section; for both subbasins, for rainfall/runoff transformation was used the modified Clark model (Kull and Feldman, 1998; Peters and Easton, 1996), that allows using a semi-distributed approach and considering explicitly physical processes space variability. For hydrological losses was used a gridded SCS-CN model (SCS, 1971, 1986), while for flood wave propagation was used the Lag model (Pilgrim and Cordery, 1993).

The Meteorologic model was a gridded precipitation, distributed from rain gauges data with isohyetes method every $30 \mathrm{~min}$

The hydrologic model calibration and verification are performed for the following flood events:

- AMCI class: calibration event 05/11/2005, control event 10/12/2006;

- AMCII class: calibration events 22/02/2006, 30/01/2001, control event 25/03/2007;

- AMCIII class: calibration events 04/12/2005, 06/12/2005, control event 10/12/2005.

In Fig. 5 calibration and validation of hydrologic model for AMCIII class are shown. To evaluate model performance, two indicators were considered (Table 6).

The Root Mean Squared Error (RMSE, Eq. 1) measures the overall agreement between observed and modelled events. It has non-negative value and no upper bound. If the model were perfect, RMSE would be zero.

$\mathrm{RMSE}=\sqrt{\frac{\sum_{i=1}^{n}\left(Q_{i}-\hat{Q}_{i}\right)^{2}}{n}}$

In Eq. (1), $Q_{i}$ and $\hat{Q}_{i}$ are the observed and the modelled values at time $i$, with $n$ total number of time intervals. Generally, for high flows this index can provide good measure of model performance (Karunanithi et al., 1994)

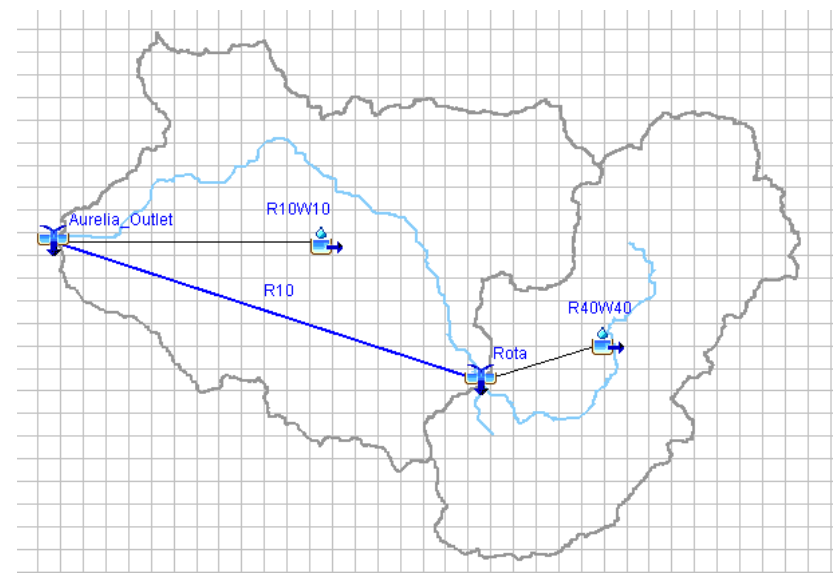

Fig. 4. Mignone model in HMS.

Table 6. Hydrological model performance.

\begin{tabular}{lrll}
\hline & & RMSE & $C E$ \\
\hline \multirow{2}{*}{ AMCI } & calibration event $(05 / 11 / 2005)$ & 35.90 & 0.51 \\
& control event $(10 / 12 / 2006)$ & 31.50 & 0.31 \\
\hline \multirow{4}{*}{ AMCII } & calibration event $(22 / 02 / 2006)$ & 61.70 & 0.78 \\
& calibration event $(30 / 01 / 2001)$ & 39.46 & 0.00 \\
& control event $(25 / 03 / 2007)$ & 28.87 & 0.66 \\
\hline \multirow{2}{*}{ AMCIII } & calibration event $(04 / 12 / 2005)$ & 33.11 & 0.59 \\
& calibration event $(06 / 12 / 2005)$ & 23.51 & 0.84 \\
& control event $(10 / 12 / 2005)$ & 15.29 & 0.96 \\
\hline
\end{tabular}

The other indicator used is the Coefficient of Efficiency ( $C E$; Nash and Sutcliff, 1970, Eq. 2), that is proportional to variance of observed data. $C E$ can range between minus infinity and one, which represents a perfect model. If $C E$ is zero, there is no difference between using the mean of observed data or simulated values. If $C E$ is negative, the mean of observed data is better then the model.

$C E=1-\frac{\sum_{i=1}^{n}\left(Q_{i}-\hat{Q}_{i}\right)}{\sum_{i=1}^{n}\left(Q_{i}-\bar{Q}\right)}$

In Eq. (1), $Q_{i}$ and $\hat{Q}_{i}$ are the observed and the modelled values at time $i$, with $n$ total number of time intervals, and $\bar{Q}$ is the mean of observed data.

The Table 6 shows that the model with best performance is the AMCIII condition model. In fact, RMSE and mainly $C E$ tends to optimal values for control events. For AMCII condition model, the performance varies between the calibrations events, for which there are a good $C E$ but a bad RMSE, or a good RMSE and a zero $C E$. Anyway, for the control event the model shows an overall good performance. For AMCI 

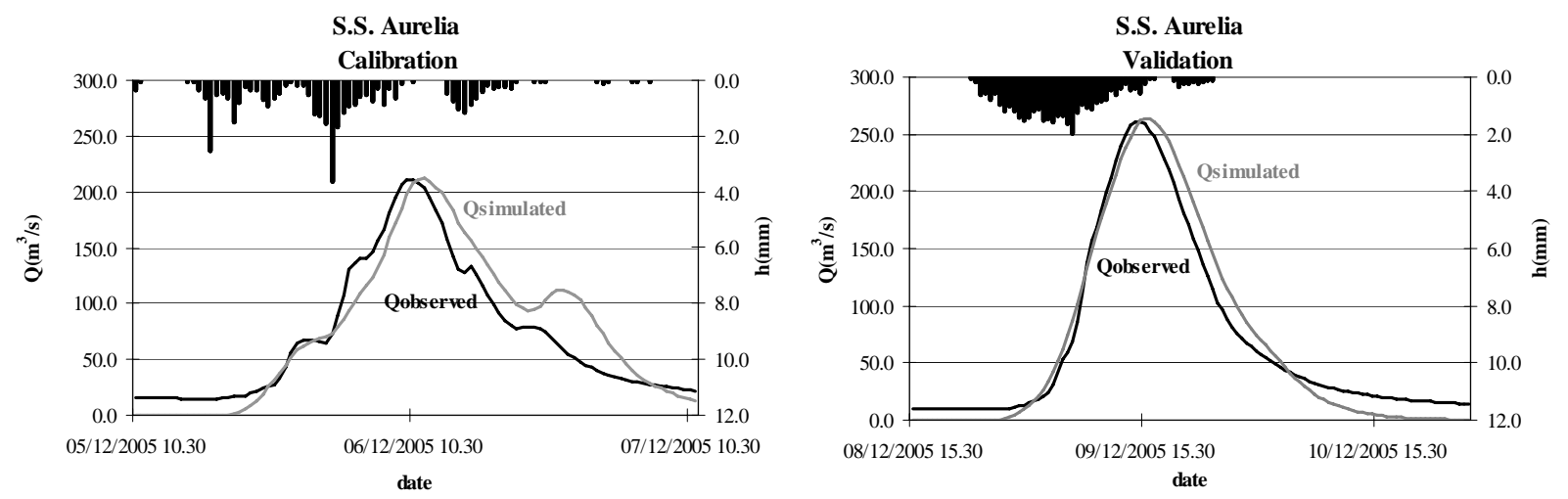

Fig. 5. Calibration and control of class AMC III hydrologic model for the Mignone River basin on the base of the observed hydrographs at "S.S. Aurelia" gauge station in December 2005.

Table 7. Hydrologic parameters values.

\begin{tabular}{lll}
\hline AMCI Class & $\begin{array}{l}\text { Subbasin } \\
\text { S.S. Aurelia }\end{array}$ & $\begin{array}{l}\text { Subbasin } \\
\text { Rota }\end{array}$ \\
\hline Initial Abstraction Ratio & 0.2 & 0.2 \\
Potential Retention Scale Factor & 0.35 & 0.35 \\
Time of Concentration $(h)$ & 6.59 & 5.21 \\
Storage Coefficient $(h)$ & 5.54 & 3.01 \\
Lag (min) & 312 & - \\
\hline AMCII Class & Subbasin & Subbasin \\
& S.S. Aurelia & Rota \\
\hline Initial Abstraction Ratio & 0.10 & 0.20 \\
Potential Retention Scale Factor & 0.30 & 0.23 \\
Time of Concentration $(h)$ & 6.09 & 6.11 \\
Storage Coefficient $(h)$ & 4.72 & 2.14 \\
Lag (min) & 276 & - \\
\hline AMCIII Class & Subbasin & Subbasin \\
& S.S. Aurelia & Rota \\
\hline Initial Abstraction Ratio & 1 & 1 \\
Potential Retention Scale Factor & 0.10 & 0.30 \\
Time of Concentration $(h)$ & 4.65 & 3.84 \\
Storage Coefficient $(h)$ & 3.94 & 3.50 \\
Lag (min) & 275 & - \\
\hline
\end{tabular}

condition model there is the worst performance, mainly for the low $C E$ values.

In Table 7 are summarized all the numerical values of the model parameters.

\subsection{Rainfall thresholds evaluation}

The inverse hydrologic problem was solved to identify the rainfall fields configuration that implies the critical discharge value overcoming. Several scenarios were simulated, analyzing basin response to 4 hyetotypes (Rosso, 2002):
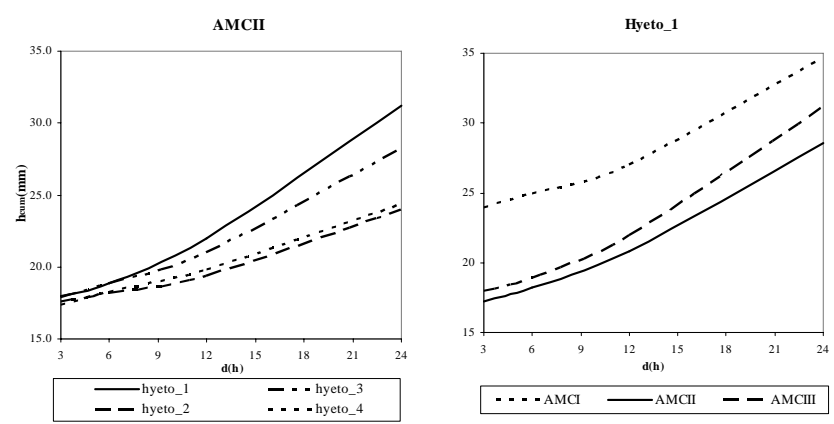

Fig. 6. Rainfall thresholds for different hyetotype, fixing class AMC II, and for different AMC classes for the step hyetograph (Hyeto 1). In ordinate the cumulative rainfall amount (in millimeter), in abscissa the duration (in hours).

- step hyetograph (Hyeto 1);

- triangular increasing rate hyetograph (Hyeto 2);

- triangular decreasing rate hyetograph (Hyeto 3);

- isosceles triangular hyetograph (Hyeto 4).

Given hyetotype, rain duration $d$ and initial soil imbibition condition based on AMC index, it was investigated the critical cumulative rainfall depth. Indipendent simulations were performed for all the combination of duration $(3,6,12$ and $24 \mathrm{~h}$ ), hyetotypes and AMC classes. The rainfall thresholds are iterative identified, by trial and error until the critical discharge value was reached. In Fig. 6 are shown AMC II rainfall thresholds for different hyetotypes and step hyetograph rainfall thresholds for different AMC classes. 


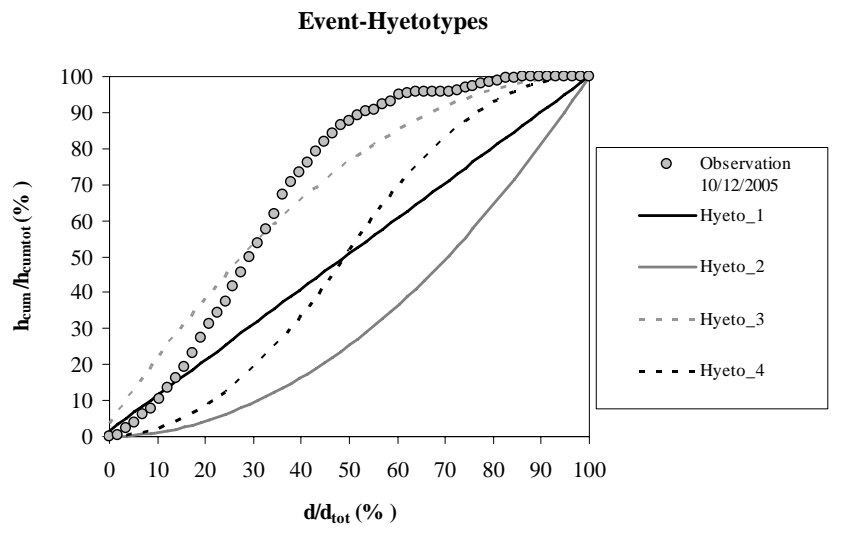

Fig. 7. Association to hyetotype: in ordinate $\%$ cumulative rainfall, in abscissa \% duration. Event 10/12/2005.

\section{Preliminary results: reliability evaluation}

In this work the reliable thresholds were tested following these steps:

- identification of significative duration $d^{*}$ and association of observed pluviometric events with a standard hyetotype;

- reliability evaluation in terms of right, false and missed alarms.

Preliminary it was necessary to establish some criteria for determining the beginning of actual runoff $\left(d^{*}\right.$, from when cumulative rainfall amounts were calculated) and for dividing precipitation events. Two parameters have been fixed (Rosso, 2002):

- significant rain: value of cumulative rainfall, discriminating between state of rain and of not-rain, identified with initial infiltration of the loss model;

- system relaxation time: time of concentration of the river basin closed to the critical cross section.

To identify the reference hyetotype, given the irregularity of real hyetographs, a "likelihood" approach is used. The hyetotype was estimated considering a differences minimization. An example is shown in Fig. 7, for the event observed on $10 / 12 / 2005$.

To estimate the rain thresholds reliability is necessary to investigate on the presence of any missed alarms or false alarms. It is defined:

- missing alarm (MA): the flood event exceeds the critical reference discharge in the critical cross section, but the recorded precipitation does not exceed the rainfall threshold.

- false alarm $(F A)$ : the rainfall threshold is overcame, but the observed discharge is lower than critical reference discharge.
Table 8. Two-by-two contingency table.

\begin{tabular}{lccc}
\hline & & \multicolumn{2}{c}{ Forecasts } \\
Observations & Warning W & No Warning W & Total \\
\hline Event E & $h$ & $m$ & $e$ \\
Non Event $\mathrm{E}^{\prime}$ & $f$ & $c$ & $e^{\prime}$ \\
Total & $w$ & $w^{\prime}$ & $n$ \\
\hline
\end{tabular}

Obviously presence of $F A$ and above all of $M A$ invalidate rainfall thresholds reliability as warning tool. A possible way to assess the performance of the proposed method is using a two-by-two contingence table, as illustrated in Table 8. The table is structured as follows: the $n$ observations are divided in Event E (critical discharge overcame) and Non Event E (critical discharge not overcame). If an event occurred and a warning was issued the outcome is an hit (with $h$ the total number of hits); if an event did not occur but a warning was issued the outcome is a false alarm, (with $f$ the total number of false alarms); if an event occurred but warning was not issued the outcome is a missed alarm, (with $m$ the total number of misses); if an event did not occur and a warning was not issued the outcome is a correct rejection, (with $c$ the total number if correct rejections). The total number of warning is $w$, of no warning $w^{\prime}$, the total number of event $e$ and of non event $e^{\prime}$.

The performance can be evaluated in terms of hit rate and false alarm rate, defined as follows:

hit rate $=\frac{h}{h+m}=\frac{h}{e}$

false alarm rate $=\frac{f}{f+c}=\frac{f}{e^{\prime}}$

The threshold based forecasting system has a good performance if the hit-rate exceeds the false-alarm rate.

\subsection{Reliability evaluation performed on pluviometric data}

In Figs. 7 and 8 show the steps for reliability evaluation for the 10/12/2005 event. At first (Fig. 7) the actual hyetograph was associated with the standard hyetotype by differences minimization; the best adaptation was with triangular decreasing rate hydrograph (Hyeto 3 ). The event belongs to AMCIII class, so the reference threshold is AMCIII-Hyeto 3 , that is overcame (Fig. 8. left graph) after $5.5 \mathrm{~h}$ from the beginning of significative rain. In the right graph (Fig. 8) is shown the observed hydrograph, with the instant of threshold and critical discharge overcoming. The lead time is $3.5 \mathrm{~h}$. The two-by-two contingency table is shown in Table 9. The corresponding hit and false alarm rate are: 

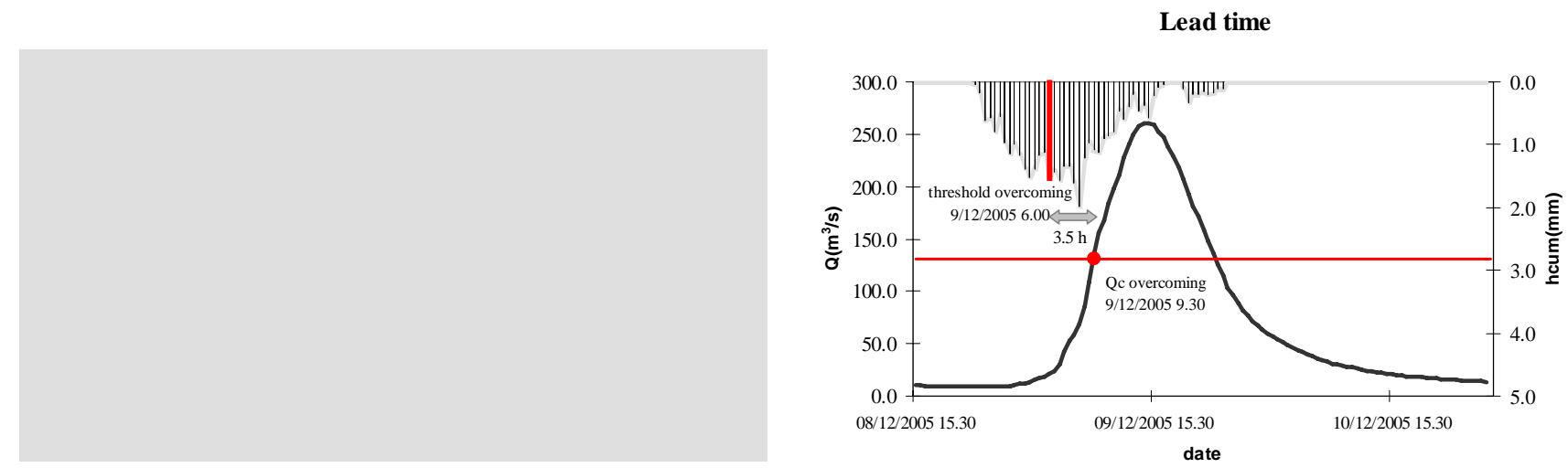

Fig. 8. Example of rainfall thresholds reliability evaluation.

Table 9. Rain gauges events: two-by-two contingency table.

\begin{tabular}{lccc}
\hline Observations & Warning W & $\begin{array}{l}\text { Forecasts } \\
\text { No Warning W }\end{array}$ & Total \\
\hline Event E & 19 & 1 & 20 \\
Non Event E' & 6 & 2 & 8 \\
Total & 25 & 3 & 28 \\
\hline
\end{tabular}

- hit rate $=0.95$

- false alarm rate $=0.75$

The mean lead time, when a warning is correctly issued, is $8.5 \mathrm{~h}$, that allows to alert the emergency system. On the basis of this results, for pluviometric data the threshold based forecasting system seems to have a good performance. On the other hand, the false alarm rate is quite high. False alarm were issued when there were long period of rain, but low intensity. So there was the time for the basin to drain the runoff without high peak discharge, even if the cumulated rainfall overcame the reference threshold. Therefore, the false alarm rate seems to depend from the infiltration dynamic, and it would be probably lower identifying differently the significant rain.

To sum up, the described threshold based forecasting system using rain gauges data works well when the rain event is short and intense, and gives problems in terms of false alarm with long low intensity events.

\subsection{Reliability evaluation performed on radar data}

From radar data only the November 2003 event was critical for Mignone River (Fig. 9), for which a warning based on calculated thresholds is obtained. The lead time is more than $24 \mathrm{~h}$. For the same event, also using rain gauges data the warning is correctly issued, even if the lead time is only of $8 \mathrm{~h}$. It seems that using radar data, the warning system

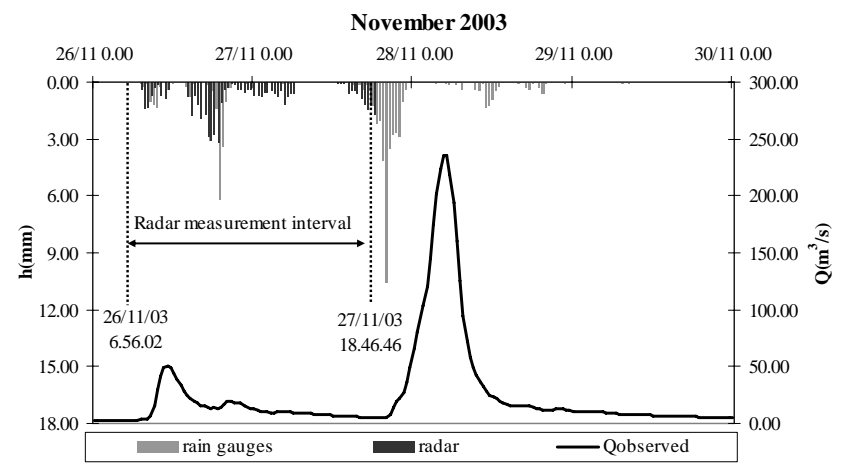

Fig. 9. November 2003: rain gauges and radar data.

works better, but to completely evaluate the performance also the presence of false alarms was investigated, and results are summarised in the two-by-two contingency table (Table 10). The corresponding hit and false alarm rate are:

- hit rate $=1$

- false alarm rate $=0.10$

The results highlight a very good performance, but it is limited by the characteristics of the available data set. In fact, as illustrated in par. 3.2.3, radar measurements were generally not taken during flood events, and the rainfall depth estimated from radar reflectivity was generally very low, corresponding to ordinary discharge value for critical section. Moreover, the presence of the false alarm seems due to an overestimated rainfall depth from radar data, and this probably explain also the long lead time obtained. In conclusion, the threshold based forecasting system gives encouraging results using radar measurements, but it is need to test the performance on a more consistent radar data set.

\subsection{Advantages of flood rainfall threshold approach}

When the hydrologic model is calibrated, it is possible to perform directly rainfall-runoff simulation with observed data, 
Table 10. Radar events: two-by-two contingency table.

\begin{tabular}{rlll}
\hline & & Forecasts & \\
Observations & Warning W & No Warning W' & Total \\
\hline Event E & 1 & 0 & 1 \\
Non Event $E^{\prime}$ & 1 & 9 & 10 \\
Total & 2 & 8 & 11 \\
\hline
\end{tabular}

Threshold approach vs. Hydrologic simulation

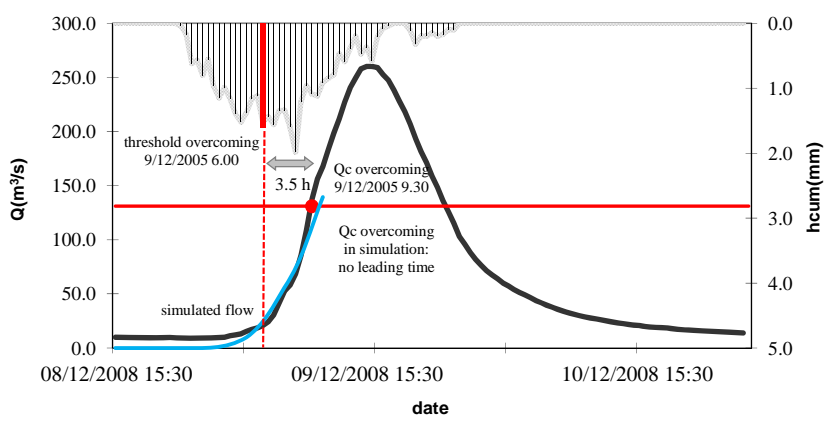

Fig. 10. Comparison between threshold approach and simulation model.

instead of comparing observed value with reference thresholds. Nevertheless, the rainfall threshold approach is more convenient in term of leading time. In fact, using observed precipitation for forcing rainfall runoff model can reproduce the actual situation, but not in advance: the critical discharge is simulated in the same time it is actually reached, so hydrological simulation can not be used as forecasting system (Fig. 10).

A possibility of using calibrated hydrologic model for forecasting could be to force the model with forecasted precipitation, for different leading time, in on-line mode. Clearly, the uncertainty about the performance of the model raises by increasing the leading time and there is the need to refresh the model when new observed data are available. Thus using the calibrated hydrologic model in off-line mode as in the rainfall thresholds approach seems to be more useful in a practical warning framework.

\section{Conclusions}

This work shown an operative case study of a rainfall thresholds definition methodology. Threshold overcoming triggers the prevention and emergency system alert. Thresholds were identified by simulation from rain gauges data and then their reliability was performed on both rainfall recorded data and radar data. Using rain gauges data the thresholds hit-rate is $95 \%$, using radar data is $100 \%$. It follows that for Mignone River basin flood warning based on rainfall thresholds seems to be an effective and immediate tool. However, it must be underlined that thresholds reliability was tested on few events, especially for radar data and further validation are required.

Acknowledgements. The authors would like to thank Ufficio Idrografico e Mareografico of Lazio Region for providing hydrometric and pluviometric data, and Institute of Atmospheric Sciences and Climate of the National Research Council for providing radar data. The research has been partially supported by CNRGNDCI. In addition, authors would like to thank the reviewers for their useful comments, which helped to improve the manuscript.

Edited by: G. Roth

Reviewed by: S. Manfreda and another anonymous referee

\section{References}

Annunziati, A., Focardi, A., Focardi, P., Martello, S., and Vannocci, P.: Analysis of the rainfall thresholds that induced debris flows in the area of Apuan Alps - Tuscany, Italy, Plinius Conference '99: Mediterranean Storms, Ed. Bios., 485-493, 1999.

Agenzia Regionale per la Protezione Ambientale Piemonte, Manuale d'uso del sistema di allertamento per situazioni di rischio idrogeologico derivanti da condizioni meteoidrologiche critiche, Direzione Regionale Servizi Tecnici di Prevenzione - Settore Meteoidrografico e reti di Monitoraggio, 2001.

Brath, A., Castellarin, A., Franchini, M., and Galeati, G.: Estimating the index flood using indirect methods, Hydrolog. Sci. J., 46(3), 399-418, 2001.

Carpenter, T. M., Sperfslage J. A., Georgakakos K. P., Sweeney, T., and Fread, D. L.: National threshold runoff estimation utilizing GIS in support of operational flash flood warning systems, J. Hydrol., 224, 21-44, 1999.

Crosta, G. B. and Frattini, P.: Rainfall thresholds for soil slip and debris flow triggering, Proceedings of the EGS 2nd Plinius Conference on Mediterranean Storms, Ed. Bios., 463-488, 2000.

Dalrymple, T.: Flood frequency analyses, Water Supply Paper 1543-A, US Geol. Survey, Reston, Virginia, USA, 1960.

Georgakakos, K. P.: Analytical results for operational flash flood guidance, J. Hydrol., 317, 81-103, 2006.

Georgakakos, K. P.: Real time prediction for flood warning and management, U.S.-Italy Research Workshop on the Hydrometeorology, Impacts, and Management of Extreme Floods Perugia (Italy), November 1995, 1995.

Hydrologic Engineering Center: Geospatial Hydrologic Modeling Extension HEC-GeoHMS: User's Manual, U.S. Army Corps of Engineers, Davis, CA, 281 pp., 2003a.

Hydrologic Engineering Center: Hydrologic Modeling System (HEC-HMS): Release Notes, U.S. Army Corps of Engineers, Davis, CA, USA, 280 pp., 2003 b.

Kirkby, M. J.: Tests of the random network model and its application to basin hydrology, Earth Surf. Processes, 1, 197-212, 1976.

Koutsoyiannis, D. and Xanthopoulos, T.: Engineering Hydrology, Edition 3, National Technical University of Athens, Athens, Greece, 418 pp., 1999.

Kull, D. W. and Feldman, A. D.: Evolution of Clark's unit graph method to spatially distributed runoff, Journal of Hydrologic. Engineering ASCE, 3(1), 9-19, 1998. 
Karunanithi, N., Grenney, W., Whitley, D. and Bovee, K.: Neural networks for river flow prediction, J. Comput. Civil Eng., 8(2), 201-220, 1994.

Lombardo F., Napolitano F., Russo F., Scialanga G., Baldini, L., and Gorgucci, E.: Rainfall estimation and ground clutter rejection with dual polarization weather radar, Advances in Geosciences, 7, 127-130, 2006.

Mancini, M., Mazzetti P., Nativi, S., Rabuffetti, D., Ravazzani, G., Amadio, P., and Rosso, R.: Definizione di soglie pluviometriche di piena per la realizzazione di un sistema di allertamento in tempo reale per il bacino dell'Arno a monte di Firenze, Proc. XXVII Convegno di idraulica e Costruzione Idrauliche, Italy, 2, 497-505, 2002

Martina, M. L. V., Todini, E., and Libralon, A.: A Bayesian decision approach to rainfall thresholds based flood warning, Hydrol. Earth Syst. Sci., 10, 413-426, 2006, http://www.hydrol-earth-syst-sci.net/10/413/2006/.

Mason, S. J. and Graham, N. E.: Conditional Probabilities, Relative Operating Characteristics and Relative Operating Levels, Weather Forecast., 14, 713-725, 1999.

Mesa, O. J. and Mifflin, E. R.. On the relative role of hillslope and network geometry in hydrologic response, in: Scale Problems in Hydrology, D. Reidel, edited by: Gupta, V., Rodriguez-Iturbe, I., and Wood, E., 1-17, Dordrecht, The Netherlands, 1986.

Naden, P. S: Spatial variability in flood estimation for large catchments: the exploitation of channel network structure, J. Hydrol. Sci., 37(1-2), 53-71, 1992.

Nash, J. E. and Sutcliffe, J. V.: River flow forecasting through conceptual models 1: a discussion of principles, J. Hydrol., 10(3), 282-290, 1970
Neary, D. G. and Swift, L. W.: Rainfall thresholds for triggering a debris flow avalanching event in the southern Appalachian Mountains, Rew. Eng. Geol., 7, 81-95, 1987.

Peters, J. C. and Easton, D. J.: Runoff Simulation Using Radar Rainfall Data, Water Resour. Bull., 32(4), 753-760, 1996.

Pilgrim, D. H. and Cordery, I.: Flood runoff, in: Handbook of hydrology, edited by: Maidment, D. R., McGraw-Hill, New York, NY, USA, 9, 1-42, 1993.

Rodriguez-Iturbe, I. and Valdes, J. B.: The geomorphologic structure of hydrologic response, Water Resour. Res., 15(6), 14091420, 1979.

Rosso, R.: Manuale di Protezione Idraulica del Territorio, Cusl, Milano, Italy, 2002.

Russo, F., Napolitano, F., and Gorgucci, E.: Rainfall monitoring systems over an urban area: the city of Rome, Hydrol. Process., 19(5), 1007-1019, 2005.

Soil Conservation Service: National engineering handbook, Cross section 4: Hydrology, US Department of Agriculture, Springfield, VA, USA, 1971.

Soil Conservation Service: Urban hydrology for small watersheds, Technical Release 55, US Department of Agriculture, Springfield, VA, USA, 1986.

Regione Lazio website (http://www.regione.lazio.it), Regione Lazio Dipartimento Territorio, Piano di tutela delle acque, Bacini idrografici e schede riassuntive per bacino, 170 pp., 2006.

Regione Lazio website (http://www.regione.lazio.it), Regione Lazio Dipartimento Territorio, Piano di tutela delle acque, Geologia, Idrogeologia e Vulnerabilit del territorio, 98 pp., 2006.

Yu, P. S. and Yang, T. C.: Using synthetic flow duration curves for rainfall-runoff model calibration at ungauged sites, Hydrol. Process., 14, 117-133, 2000. 